\title{
Commentary on: "The body social: an enactive approach to the self." A tool for merging bodily and social self in immobile individuals
}

\author{
Giulia Galli $^{1 *}$ and Mariella Pazzaglia ${ }^{1,2 *}$ \\ ${ }^{1}$ IRCCS Santa Lucia Foundation, Rome, Italy, ${ }^{2}$ Department of Psychology, University of Rome "La Sapienza," Rome, Italy
}

Keywords: embodiment, tool use, spinal cord injuries, bodily self, social self

\section{A commentary on}

The body social: an enactive approach to the self

by Kyselo, M. (2014). Front. Psychol. 5:986. doi: 10.3389/fpsyg.2014.00986

OPEN ACCESS

Edited by:

Snehlata Jaswal,

Indian Institute of Technology Jodhpur,

India

Reviewed by:

Daniele Romano,

University of Milano-Bicocca, Italy

Sahba Besharati,

King's College London, UK

*Correspondence.

Giulia Galli,

g.galli@hsantalucia.it;

Mariella Pazzaglia,

mariella.pazzaglia@uniroma1.it

Specialty section:

This article was submitted to Cognitive

Science, a section of the journal

Frontiers in Psychology

Received: 11 November 2014 Accepted: 03 March 2015

Published: 19 March 2015

Citation:

Galli G and Pazzaglia M (2015) Commentary on: "The body social: an enactive approach to the self." A tool for merging bodily and social self in immobile individuals.

Front. Psychol. 6:305

doi: 10.3389/fpsyg.2015.00305
The article by Miriam Kyselo titled "The body social: an enactive approach to the self” (Kyselo, 2014) raises a crucial issue and discusses how bodily and social aspects may merge together in a unique account of the human self. The author rightly suggests that we do not have to choose between the bodily and social dimensions of self.

The integration process between bodily and social self may fail in patients with a number of neurological and psychiatric diseases, as well as during certain experimental conditions (Lucci and Pazzaglia, 2015). Various neurological conditions produce disturbed self perceptions, for example disownership of one's hand in somatoparaphrenia (Vallar and Ronchi, 2009; Romano et al., 2014), desire for amputation in body integrity identity disorder (Sedda, 2011), unintended movements in alien hand syndrome (Della Sala et al., 1991), ownership for supernumerary limbs (Guterstam et al., 2011) or seeing own body from a third person perspective in out of body experiences (Blanke and Arzy, 2005). The illusory alterations of awareness of the bodily self can be also induced experimentally during the so-called "rubber hand illusion"-RHI (Botvinick and Cohen, 1998), where the subjective perceptual experience interfere with bodily self and the external bodily-shaped object is treated as part of the body. These clinical populations and experimental condition may challenge Kyselo's view, as bodily self could be disrupted despite a normal social self.

However, an example of the complementarity of bodily and social self are patients with spinal cord injury (SCI). "The loss of self is inherent in the social isolation of paralytics, who have furthermore become separated from their bodies by neural damage, and from their former identities by society" (Murphy, 2001; p. 227). SCI can leave a part of the body insensible and immobile, leading to specific disorders in the mental representation of one's own body and the sense of bodily self (Lenggenhager et al., 2012, 2013). After SCI, patients see their former life slip away and become restricted, and the social implications can be considerable. They must adapt to their new body and make significant changes in the way they function in the world. Here we propose that a medium that accepts self-multiplicity while also offering an integrative perspective on the self is possible. We consider how an assistive tool can change the manner in which people with massive disconnection between body and brain access to social world.

For people who chose to integrate their disability into their full sense of self, the wheelchair represents a changing paradigm, as highlighted by significant theoretical models (Papadimitriou, 2008; Standal, 2011) and experimental studies (Arnhoff and Mehl, 1963; Winance, 2006a,b; Higuchi et al., 2009; Olsson, 2012; Fuentes et al., 2013; Pazzaglia et al., 2013). When patients do not 
perceive the loss or limitation and instead focus on the power and joy of seeing the world, "I could whiz around and feel the wind in my face again. Just being out on the street was exhilarating" (Austin, 2014), the wheelchair becomes a symbol of both physi$\mathrm{cal}$ and social independence for the body injured. Even for people with life-threatening illnesses, this tool provides a way to be out in the world, continuing their lives and accessing the many realms of human experience (Karp, 2008).

The plastic shaping of the bodily self has already been demonstrated by multiple neuropsychological studies showing that tools can be integrated into the representation of one's own body (Maravita and Iriki, 2004; Cardinali et al., 2009; Tsakiris, 2010; Longo and Serino, 2012). In the process, known as embodiment, the tool is processed in the same way as a part of one's body (De Vignemont, 2011), allowing a new connection between the sense of having a modified functional body and the sense of self. In the case of SCI, the wheelchair, which contributes to the individual's conscious movement, can be added to the dynamic representation of patients' bodily self. From a physical perspective, the corporeal awareness of a tool emerges as the functional self with its new rules and novel ways of interacting with the world (Pazzaglia et al., 2013). Through the use of the wheelchair, the perceived bodily self is that of being functionally whole, enabling the immobile user to act in the world again.

The wheelchair becomes a vehicle of freedom of mobility and independence for newly abled adults, reconstructing their sense of self (Papadimitriou, 2008). A deep embodiment process of the en-wheeled body can occur, enhanced for both the loss of sensorimotor function (Pazzaglia et al., 2013) and the critical sense of protection and monitoring (Rossetti et al., 2015).

From a social perspective, the injury affects consciousness as it introduces a novel pervasive identity. The tool incorporation process described above involves new ways of being in the world, i.e., the relations between self and others and the world (Winance, 2006a,b; Papadimitriou, 2008). The wheelchair increases permeability of the boundary between disabled and non-disabled individuals, directly mitigating the impairment and thereby helping the user escaping disability (Nario-Redmond et al., 2013). Functional and smooth wheelchair use significantly contributes to the production of a new identity and allows the individual to cope with his disability by emphasizing one's strengths, interests, and efficacy. It has the liberating aspect of providing opportunities to participate in social activities, through the new form of the body. In this case, disablement is not simply a physical affair; rather, it is a lifelong process of adjusting to changed circumstances (Pentland et al., 2002) that ultimately results in a transformation from disabled to newly abled. Being active and engaged constitutes a starting point for restructuring the social self. Emerging empirical data support the importance of the social context in shaping self-perceptions after a SCI (Fuhrer,

\section{References}

Altman, B. M. (2001). "Disability definitions, models, classification schemes, and applications," in Handbook of Disability Studies, eds G. L. Albrecht, K. D. Seelman, and M. Bury (Thousand Oaks, CA: Sage), 97-122. doi: 10.4135/9781412976251.n4
1996). Several surveys of patients with SCI revealed that their self-reported quality of life was only slightly different from that of control subjects without SCI (Stensman, 1994). Moreover, the quality of life for this population, regardless of severity of impairment, consisted of various themes (Manns and Chad, 2001) such as accessibility, emotional well-being, stigma, spontaneity, relationships and social function, occupation, finances and independence, additionally to the expected physical variables such as functionality and physical well-being. Similarly, patients with locked-in syndrome can adjust very well to the objective physical change and actually feel the same as before (Nizzi et al., 2012), although changes in their self-awareness and quality of life are not mediated by any functional prosthetic tool, which in this case would not have the meaning of unifying bodily and activity extremely restricted of social self.

The effort to understand how people maintain psychological well-being despite physical and social challenges is a core topic of many human sciences. The field has shifted from a medical model of disability as a functional limitation of living without movement and sensation, to a social model that includes consequent relational problems (Altman, 2001; Williams, 2001; Cole, 2004; Darling and Heckert, 2010). Both physical and emotional adjustments that follow wheelchair use could result in a new bodily and social-self representation, in which the person may incorporate the wheelchair (Fuentes et al., 2013; Pazzaglia et al., 2013). Bodily changes can affect and be integrated into our self as a disordered organism regains a state of order (Goldstein, 1939). The fact that quality of life often equates with social rather than physical status (Gosseries et al., 2009) makes sense when the boundaries of self are not determined by bodily processes alone, but are instead plastic in terms of relational and social interactions. Although the relationship between actual bodily states and embodied cognition has been widely explored, little is known about how changes in the connection between brain and body periphery, occurring after a traumatic SCI, influence higher-level embodied self such as perspective-taking, inter-subjectivity and group membership, which makes these topics extremely challenging for future investigations.

As an individual has to change adaptively (Thompson, 2007) by flexibly regulating his own identity (Di Paolo, 2005), it is likely that when discussing individuality, SCI patients do not view their self as primarily physical or social, but rather including both aspects of self-definition and the embodiment of the functional tool that permits them to re-negotiate their self as a whole.

\section{Acknowledgments}

Funded by the International Foundation for Research in Paraplegie (IRP, P133).

Arnhoff, F., and Mehl, M. (1963). Body image deterioration in paraplegia. J. Nerv Ment. Dis. 137, 88-92. doi: 10.1097/00005053-196307000-00010

Austin, S. (2014). TED Blog. Available online at: http://blog.ted.com/ 2013/01/08/see-much-more-of-sue-austins-incredible-wheelchair-art/

Blanke, O., and Arzy, S. (2005). The out-of-body experience: disturbed self-processing at the temporo-parietal 
junction. Neuroscientist 11, 16-24. doi: 10.1177/107385840 4270885

Botvinick, M., and Cohen, J. (1998). Rubber hands 'feel' touch that eyes see. Nature 391, 756. doi: 10.1038/35784

Cardinali, L., Frassinetti, F., Brozzoli, C., Urquizar, C., Roy, A. C., and Farne, A. (2009). Tool-use induces morphological updating of the body schema. Curr. Biol. 19, R478-R479. doi: 10.1016/j.cub.2009.06.048

Cole, J. (2004). Still Lives. Cambridge: MIT press.

Darling, R. B., and Heckert, D. A. (2010). “Activism, models, identities, and opportunities: a preliminary test of a typology of disability orientations, in Disability as a Fluid State: Research in Social Science and Disability, ed S. N. Barnartt (Bingley, UK: Emerald Group Publishing Limited), 203-229. doi: 10.1108/S1479-3547(2010)0000005011

Della Sala, S., Marchetti, C., and Spinnler, H. (1991). Right-sided anarchic (alien) hand: a longitudinal study. Neuropsychologia 29, 1113-1127. doi: 10.1016/00283932(91)90081-I

De Vignemont, F. (2011). Embodiment, ownership and disownership. Conscious. Cogn. 20, 82-93. doi: 10.1016/j.concog.2010.09.004

Di Paolo, E. (2005). Autopoiesis, adaptivity, teleology, agency. Phenomenol. Cogn. Sci. 4, 429-452. doi: 10.1007/s11097-005-9002-y

Fuentes, C. T., Pazzaglia, M., Longo, M. R., Scivoletto, G., and Haggard, P. (2013). Body image distortions following spinal cord injury. J. Neurol. Neurosurg. Psychiatry 84, 201-207. doi: 10.1136/jnnp-2012-304001

Fuhrer, J. J. (1996). The subjective wee-being of people with spinal cord injury: relationships to impairment, disability and handicap. Top. Spinal Cord Inj. Reahbil. $1,56-71$.

Goldstein, K. (1939). The Organism: A Holistic Approach to Biology. Boston, MA: Beacon Press.

Gosseries, O., Bruno, M. A., Vanhaudenhuyse, A., Laureys, S., and Schnakers, C. (2009). "Consciousness in the locked-in syndrome" in The Neurology of Consciousness, eds S. Laureys and G. Tononi (Oxford: Elsevier), 191-203. doi: 10.1016/B978-0-12-374168-4.00015-0

Guterstam, A., Petkova, V. I., and Ehrsson, H. H. (2011). The illusion of owning a third arm. PLoS ONE 6:e17208. doi: 10.1371/journal.pone.0017208

Higuchi, T., Hatano, N., Soma, K., and Imanaka, K. (2009). Perception of spatial requirements for wheelchair locomotion in experienced users with tetraplegia. J. Physiol. Anthropol. 28, 15-21. doi: 10.2114/jpa2.28.15

Karp, G. (2008). Life on Wheels. New York, NY: Demos Health; Springer Publishing.

Kyselo, M. (2014). The body social: an enactive approach to the self. Front. Psychol. 5:986. doi: 10.3389/fpsyg.2014.00986

Lenggenhager, B., Pazzaglia, M., Scivoletto, G., Molinari, M., and Aglioti, S. M. (2012). The sense of the body in individuals with spinal cord injury. PLoS ONE 7:e50757. doi: 10.1371/journal.pone.0050757

Lenggenhager, B., Scivoletto, G., Molinari, M., and Pazzaglia, M. (2013). Restoring tactile awareness through the rubber hand illusion in cervical spinal cord injury. Neurorehabil. Neural Repair 27, 704-708. doi: 10.1177/1545968313491009

Longo, M. R., and Serino, A. (2012). Tool use induces complex and flexible plasticity of human body representations. Behav. Brain Sci. 35, 229-230. doi: 10.1017/S0140525X11001907

Lucci, G., and Pazzaglia, M. (2015). Towards multiple interactions of inner and outer sensations in corporeal awareness. Front. Hum. Neurosci. 9:163. doi: 10.3389/fnhum.2015.00163

Manns, P. J., and Chad, K. E. (2001). Components of quality of life for persons with a quadriplegic and paraplegic spinal cord injury. Qual. Health Res. 11, 795-811. doi: $10.1177 / 104973201129119541$

Maravita, A., and Iriki, A. (2004). Tools for the body (schema). Trends Cogn. Sci. 8, 79-86. doi: 10.1016/j.tics.2003.12.008

Murphy, R. (2001). The Body Silent: The Different World of the Disabled. New York, NY: W. W. Norton \& Company.

Nario-Redmond, M. R., Noel, J. G., and Fern, E. (2013). Redefining disability, re-imagining the self: disability identification predicts selfesteem and strategic responses to stigma. Self Identity 12, 468-488. doi: $10.1080 / 15298868.2012 .681118$
Nizzi, M. C., Demertzi, A., Gosseries, O., Bruno, M. A., Jouen, F., and Laureys, S. (2012). From armchair to wheelchair: how patients with a locked-in syndrome integrate bodily changes in experienced identity. Conscious. Cogn. 21, 431-437. doi: 10.1016/j.concog.2011. 10.010

Olsson, C. J. (2012). Complex motor representations may not be preserved after complete spinal cord injury. Exp. Neurol. 236, 46-49. doi: 10.1016/j.expneurol.2012.03.022

Papadimitriou, C. (2008). Becoming en-wheeled: the situated accomplishment of re-embodiment as a wheelchair user after spinal cord injury. Disabil. Soc. 23, 691-704. doi: 10.1080/09687590802 469420

Pazzaglia, M., Galli, G., Scivoletto, G., and Molinari, M. (2013). A functionally relevant tool for the body following spinal cord injury. PLoS ONE 8:e58312. doi: 10.1371/journal.pone.0058312

Pentland, W., Walker, J., Minnes, P., Tremblay, M., Brouwer, B., and Gould, M. (2002). Women with spinal cord injury and the impact of aging. Spinal Cord 40, 374-387. doi: 10.1038/sj.sc.3101295

Romano, D., Gandola, M., Bottini, G., and Maravita, A. (2014). Arousal responses to noxious stimuli in somatoparaphrenia and anosognosia: clues to body awareness. Brain 137, 1213-1223. doi: 10.1093/brain/ awu009

Rossetti, A., Romano, D., Bolognini, N., and Maravita, A. (2015). Dynamic expansion of alert responses to incoming painful stimuli following tool use. Neuropsychologia. doi: 10.1016/j.neuropsychologia.2015.01.019. [Epub ahead of print].

Sedda, A. (2011). Body integrity identity disorder: from a psychological to a neurological syndrome. Neuropsychol. Rev. 21, 334-336. doi: 10.1007/s11065-0119186-6

Standal, O. F. (2011). Re-embodiment: incorporation through embodied learning of wheelchair skills. Med. Health Care Philos. 14, 177-184. doi: 10.1007/s11019010-9286-8

Stensman, R. (1994). Adjustment to traumatic spinal cord injury. A longitudinal study of self-reported quality of life. Paraplegia 32, 416-422. doi: $10.1038 /$ sc. 1994.68

Thompson, E. (2007). Mind in Life: Biology, Phenomenology, and the Sciences of Mind. Cambridge, MA: Harvard University Press.

Tsakiris, M. (2010). My body in the brain: a neurocognitive model of body-ownership. Neuropsychologia 48, 703-712. doi: 10.1016/j.neuropsychologia.2009.09.034

Vallar, G., and Ronchi, R. (2009). Somatoparaphrenia: a body delusion. A review of the neuropsychological literature. Exp. Brain Res. 192, 533-551. doi: 10.1007/s00221-008-1562-y

Williams, G. (2001). “Theorizing disability," in Handbook of Disability Studies, eds G. L. Albrecht, K. D. Seelman, and M. Bury (Thousand Oaks, CA: Sage), 123-144. doi: 10.4135/9781412976251.n5

Winance, M. (2006a). Pain, disability and rehabilitation practices. A phenomenological perspective. Disabil. Rehabil. 28, 1109-1118. doi: $10.1080 / 09638280500531800$

Winance, M. (2006b). Trying out the wheelchair: the mutual shaping of people and devices through adjustment. Sci. Technol. Hum. Values 31, 52-72. doi: $10.1177 / 0162243905280023$

Conflict of Interest Statement: The authors declare that the research was conducted in the absence of any commercial or financial relationships that could be construed as a potential conflict of interest.

Copyright (c) 2015 Galli and Pazzaglia. This is an open-access article distributed under the terms of the Creative Commons Attribution License (CC BY). The use, distribution or reproduction in other forums is permitted, provided the original author(s) or licensor are credited and that the original publication in this journal is cited, in accordance with accepted academic practice. No use, distribution or reproduction is permitted which does not comply with these terms. 